\author{
Cadernos de \\ ESTUDOS LNGUUísTICOS - (59.1), Campinas, pp. 111-133 - jan./abr. 2017
}

\title{
A CONSTRUÇÃO METAFÓRICA DE PALAVRAS-CHAVE PARA A DESCRIÇÃO DE EXPERIÊNCIAS INTERCULTURAIS: UM ESTUDO A PARTIR DA ANÁLISE DA CONVERSA MULTIMODAL
}

\author{
ULRIKE AGATHE SCHRÖDER*
}

\begin{abstract}
RESUMO: Recentemente, uma interface emergiu entre a Linguística Cognitiva e a Análise da Conversa primeiramente como resultado de dois insights básicos: por um lado, observa-se uma demanda crescente entre linguistas cognitivos para a fundamentação de seus pressupostos teóricos com dados empíricos sólidos relacionados ao uso da língua; por outro lado, analistas da conversa tornaram-se cientes do fato de que não podem continuar a realizar pesquisas sem considerar fenômenos cognitivos, especialmente ao contemplarem que a 'máquina' conversacional, como Sacks a chamou, de fato, não funciona por conta própria. Muito pelo contrário, são os participantes com seu conhecimento individual, social e cultural que coconstroem interativamente os padrões comunicativos que estão sendo observados. Sendo assim, a questão crucial que surge a partir da relação recíproca entre as duas áreas está interligada aos aspectos cognitivos do significado contextual coconstruido. Concomitantemente, pesquisadores no campo metafórico do gesto e da cognição defrontam-se com esta nova interface que parte de um ângulo fenômeno-antropológico, corporificado e praxeológico. Isto inclui a pressuposição de que atos gestuais são preferencialmente concebidos como resultado de cognição distribuída e de coordenação situada e não como estruturas psicológicas pré-ordenadas que determinam língua e gesto em um caminho unidirecional, como proposto pela Teoria da Metáfora Conceptual da primeira geração. Porém, ainda é difícil encontrar pesquisas voltadas para interações reais partindo de uma perspectiva corporificada e multimodal, simultaneamente mantendo o referencial metodológico da Análise da Conversa, o que implica, por exemplo, uma atenção aos meios prosódicos. A seguinte análise busca contribuir para um diálogo entre as duas disciplinas por analisar como estudantes intercambistas conceitualizam suas experiências em relação à sua cultura alvo em termos de metáforas-chave exibidas em níveis multimodais e servindo como 'gatilhos' para a construção de alteridade.

Palavras-chave: Linguística Cognitiva; Análise da Conversa; Pragmática Intercultural; Metáfora gestual; alteridade.
\end{abstract}

\footnotetext{
"Universidade Federal de Minas Gerais, Belo Horizonte (MG), Brasil. schroederulrike@gmx. $\underline{\text { com }}$

Professora Associada na Universidade Federal de Minas Gerais. Eu agradeço a CNPq pela Bolsa de Produtividade, a FAPEMIG pelo apoio que recebo pelo Programa Pesquisador Mineiro (2015-2017) e agradeço a CAPES e à Fundação Humbold pelo apoio financeiro que recebi dentro do programa CAPES/HUMBOLDT Research Fellowship for experienced researchers para a realização da minha pesquisa de pós-doutorado na Universidade de Münster na Alemanha de agosto de 2013 a julho de 2014. Também agradeço à Profa. Dra. Susanne Günthner pelo convite a trabalhar no Instituto de Estudos Germânicos na WWU, bem como à Senhora Hofer da International Office, à Senhora Filler do Departamento ERASMUS e aos Senhores Schuch e Januário de Sales do Brasilienzentrum da WWU pela ajuda na busca de voluntários para minha filmagem. Finalmente, agradeço à Senhora Sülzer e ao Senhor Böcker pelo apoio técnico durante a filmagem e na transcrição.
} 
ABSTRACT: Recently, an interface between cognitive linguistics and conversation analysis has emerged mainly as a result of two basic insights: On the one hand, there is a growing demand between cognitive linguistics to put their theoretical assumptions and presuppositions onto the solid empirical grounds of language use; on the other hand, conversation analysts also have become increasingly aware of the fact that they no longer can abstain from cognitive phenomena, especially when taking into account that the conversational 'machinery', as Sacks $(1995$, p. 169) called it, does not function all by itself. Rather, the participants with their individual, social, and cultural knowledge interactively construct the communicative patterns under investigation. Hence, the pivotal question which arises from the two areas' reciprocal relationship concerns precisely the cognitive aspects of the co-constructed meaning-in-context. Currently, researchers in the field of metaphoric gesture and cognition account for this new interface which departs from a phenomenological-anthropological, embodied, as well as praxeological point of view. This includes the assumption that gestural acts are rather conceived as a result of distributed cognition and situated coordination with others than as pre-ordained psychological structures determining language and gesture in a unidirectional way, as it was proposed by the first generation of Conceptual Metaphor Theory. Nevertheless, it is still hard to find the examination of real interacion from an 'embodied' and multimodal perspective in empirical practice, concurrently maintaining the operational framework of conversation analysis which implies drawing attention simultaneously also to prosodic cues. The following analysis aims at contributing to the dialogue between the two disciplines by analysing how exchange students conceptualize their experiences within their host culture in terms of key metaphors displayed on multimodal levels and serving as triggers for the construction of alterity.

Keywords: Cognitive linguistics; Conversation analysis; Intercultural pragmatics; Gestural metaphor; alterity.

\section{INTRODUÇÃO}

O seguinte artigo apresenta um estudo na interface da Análise da Conversa, ${ }^{1}$ Pragmática Intercultural e Linguística Cognitiva para abordar, em sintonia com Schmid (2012, p. 2), os "aspectos cognitivos do construal do significado-emcontexto". ${ }^{2}$ Trata-se de uma preocupação que está sendo cada vez mais tematizada, o que, há pouco tempo, também resultou na fundação da assim chamada 'Pragmática Cognitiva', junto ao periódico com o mesmo nome. Concomitantemente, observase pretensões semelhantes na Linguística Cognitiva, iniciadas no final dos anos noventa, quando foi publicado o artigo programático de Raymond Gibbs: "Retirando a metáfora das nossas cabeças e colocando-a no mundo cultural". 3 Sendo assim, por um lado, linguistas cognitivos estão se tornando cada vez mais cientes da necessidade de apoiar seus pressupostos teóricos na sólida base empírica

\footnotetext{
${ }^{1}$ No Brasil, dois termos são usados para se referir a pesquisas do campo de estudo Conversation Analysis, oriundo dos Estados Unidos: Análise da Conversação, termo introduzido sob a égide de Marcuschi, que hoje é visto sobretudo como referente a uma vertente da Linguística Textual, ao passo que o termo Análise da Conversa Etnometodológica (ACE), ou simplesmente Análise da Conversa, surgido recentemente, é usado para se referir exclusivamente aos estudos sobre a língua falada que enfocam a articulação dos métodos de ação social humana. Esta vertente busca se voltar, dessa forma, para a tradição sociológica norte-americana (GARCEZ, 2008, p. 21). Sem se associar a uma linha específica, prefere-se aqui o termo Análise da Conversa ao invés de Conversação, em razão de conversa ter uma referência mais unívoca a qualquer atividade cotidiana de troca de palavras entre duas ou mais pessoas, enquanto conversação tende a carregar uma conotação mais restrita ou formal.

2 "cognitive aspects of the construal of meaning-in-context"

3 "Taking metaphor out of our heads and putting it into the cultural world"
} 
da língua em uso; por outro lado, analistas da conversa estão se despedindo da ideia de deixar fenômenos cognitivos de fora do seu campo de pesquisa.

Porém, ainda continua difícil encontrar na prática empírica estudos que se dediquem a interações reais abordadas a partir de uma perspectiva corporificada, e que mantenham, concomitantemente, o referencial operacional da análise da conversa. $\mathrm{O}$ estudo que apresentarei aqui pretende contribuir para o diálogo entre as duas disciplinas ao analisar como estudantes intercambistas conceitualizam suas experiências interculturais com a cultura alvo em termos de metáforas-chave exibidas em níveis multimodais, as quais servem como 'gatilho' para a construção de alteridade.

\section{A METÁFORA MULTIMODAL NA INTERAÇÃO REAL}

Junto à popularização do livro de Lakoff e Johnson (2003 [1980]), a metáfora não é mais vista como figura trópica reduzida a um ornamento retórico, mas, sim, como fenômeno cognitivo no qual há um mapeamento entre domínios no sistema conceptual, sendo que um domínio forma o domínio alvo (target domain), e o outro, o domínio fonte (source domain) da projeção metafórica. Com isso, para a $\mathrm{TMC}$, a metáfora no nível cognitivo está em primeiro plano, enquanto as expressões linguísticas são vistas apenas como reflexo na superfície de uma estrutura mais profunda. As metáforas conceptuais, por sua vez, baseiam-se em estruturas universais corporalmente entrincheiradas, a saber, em esquemas imagéticos como CAMINHO ou CONTÊINER, que correspondem à orientação antropológica fundamental do ser humano.

Nas últimas duas décadas, houve uma mudança significativa no campo de pesquisa da metáfora cognitiva, de um ângulo extracomunicativo a um ângulo comunicativo (SCHRÖDER, 2012). Em oposição à metáfora conceitual e convencional de Lakoff e Johnson, Lynne Cameron (2007, 2008), por exemplo, propõe direcionar a atenção para a metáfora discursiva, para a qual ela introduz o termo 'metaphoremes', superando a mera função epistemológica da metáfora para integrar funções pragmáticas. Segundo Cameron (2008, p. 197), as metáforas não são apenas ativadas, elas emergem no discurso de forma sistemática ao se tornarem "um fenômeno em movimento, dinâmico, que se conecta e desconecta com outras ideias e outros falantes, começa e recomeça, passa pela fala, desenvolvendo-se, estendendo-se, mudando". ${ }^{4}$ Adicionalmente, no discurso, as metáforas frequentemente são revitalizadas através de pistas de contextualização (tuning devices): like, so to speak or kind/sort of, que se tornam muito relevantes em gêneros comunicativos como, por exemplo, interações em sala de aula (CAMERON; DEIGNON, 2003).

4 "metaphor is a shifting, dynamic phenomenon that spreads, connects, and disconnects with other thoughts and other speakers, starts and restarts, flows through talk developing, extending, changing." 
Ora, além dessas pesquisas no campo da língua falada, houve um crescimento significativo de estudos multimodais, que, entre outros, também se direcionam à produção online de gestos metafóricos em conversas, promovendo interfaces com a análise da conversa. Dentre eles, destacam-se os trabalhos de David McNeill (1992), Alan Cienki (1998; 2008) e Cornelia Müller (1998; 2004). O insight psicológico-cognitivista de que gesticular e falar apenas apresentam duas facetas da língua como sistema simbólico pode ser reconduzido a McNeill; ainda que a gesticulação proceda de modo esquemático, global, composicional, holístico e sintético, a fala é arbitrária, analítica, aditiva, combinatória e linear.

A abordagem desses pesquisadores tem uma orientação mais fenomenológica, antropológica, contextual e praxeológica, porém, mantém a hipótese da corporificação, de acordo com a Linguística Cognitiva. Não obstante, o objetivo principal é trazer à luz o entrelaçamento do falar e pensar no processo conversacional ao buscar a emersão da metáfora inovativa. Com isso, essa abordagem pode ser conectada à perspectiva de Cameron. Por exemplo, Müller (2013) destaca que metáforas gestuais assumem não apenas uma função representativa, mas também uma função expressiva - como quando levantamos as mãos para cima para exprimir triunfo -, bem como uma função apelativa - quando colocamos o dedo indicador nos lábios para sinalizar ao ouvinte que ele deve ficar quieto. Outros gestos funcionam como meros atos de fala, como o gesto de jurar, com a mão aberta e levantada. Por fim, há gestos pragmáticos com função performativa, como quando eu 'passo' a palavra para outra pessoa através da mão aberta ou quando eu 'empurro para o lado' um argumento desagradável.

Müller e Cienki (2009) distinguem entre a metáfora 'monomodal' e 'multimodal'. Ao passo que a metáfora 'monomodal' apenas surge no nível linguístico ou gestual, a metáfora 'multimodal' é coexpressiva. Os autores dão o exemplo de uma conversa na qual uma mulher descreve seu amor da juventude como algo que se torna cada vez mais 'pegajoso' (klebrig), enquanto ela junta as palmas das duas mãos, pressionando-as uma contra a outra e afastando-as, repetidamente. Nos dois níveis, observa-se o mesmo domínio fonte (COLA). Já no próximo caso, a situação é diferente. Enquanto a pessoa diz: "Either your're right your're wrong y'r black 'r white y'know", 5 ela move a mão direita da esquerda para a direita. Portanto, os domínios fonte são distintos (COR e ESPAÇO).

Por último, para nossa pesquisa, a metonímia torna-se relevante. Entende-se como metonímia, de acordo com Kövecses e Radden (1998, p. 93), uma entidade conceitual na qual "a fonte fornece o acesso mental a outra entidade conceptual, o alvo, dentro do mesmo domínio ou modelo cognitivo idealizado (MCI)". ${ }^{6}$

Ao contrário da metáfora, trata-se de uma relação de contiguidade, cuja função central é direcionar a atenção a um aspecto específico, e não compreender um domínio a partir de um outro. Mittelberg e Waugh (2009) mostram que gestos

\footnotetext{
${ }^{5}$ literalmente: "ou você está certo ou errado, preto ou branco, entendeu"

6 "the source provides mental access to another conceptual entity, the target, within the same domain, or ICM"
} 
metafóricos, para serem compreendidos, no uso contextualizado, frequentemente precisam da inferência metonímica como primeiro passo cognitivo. Por exemplo, a interpretação metafórica de duas mãos que desenham os cantos de um quadro no ar para indicar o quadro de uma narração é realizada pelo interlocutor por meio de uma primeira etapa, na qual ele infere, a partir do desenho dos cantos no ar, que esse desenho se trata de um quadro e, por meio de uma segunda etapa, ele passa do quadro literal a um quadro metafórico: o quadro da narração. Este processo inclui um entendimento comprimido em relação à função que a metonímia assume como 'ponto de acesso' (LANGACKER, 1987, p. 163-164) ao nosso conhecimento enciclopédico e cultural. Tal visão também é inerente à teoria da metonímia como processo fractal multimodal, desenvolvida por Paiva (2010), com base na teoria da complexidade. Paiva recorre a Mandelbrot (1982) que, ao estudar o litoral, descobriu que seu formato exibe um determinado padrão independente da escala, ou seja, visto de perto ou de longe esses padrões são autossemelhantes. Ora, a autora frisa que, a partir da perspectiva fractal, a metonímia deve ser entendida em termos de uma mudança escalar, uma vez que a mesma coisa é vista em uma dimensão fractalizada, sem que se perca a dimensão do todo. Sendo assim, por exemplo, o capelo como uma pequena dimensão de uma formatura aciona a imagem do formando, que remete à cerimônia de formatura, que remete por sua vez ao final de um processo educacional. Destarte, o fractal, na sua função compressora, torna-se um hiperlink que nos guia pelo domínio conceitual integral. A metonímia, por conseguinte, "não é uma coisa nomeada por outra, é a mesma coisa vista em uma dimensão fractalizada sem que se perca a dimensão do todo" (PAIVA, 2010, p. 17).

Como veremos mais à frente, a experiência da 'alteridade' vivenciada pelos intercambistas é incorporada de forma multimodal, e são a metáfora e a metonímia que lançam a ponte entre o plano visível da interação e o plano invisível da cognição. Embora estudos pós-modernos tenham postulado repetidamente como essencialista o pensamento de pesquisadores que afirmam a existência de 'diferenças culturais', uma questão que continua em aberto é se a negação dessas culturas reflete de forma apropriada a perspectiva do próprio participante de uma experiência intercultural, uma vez que as próprias pessoas ainda continuam frequentemente a negociar verbalmente seus encontros com outras culturas por meio de categorias habituais, tais como 'nacionalidade' ou 'cultura' (SCHRÖDER; CARNEIRO MENDES, 2015; DREHER, 2007). Este comportamento é ancorado antropologicamente no conceito de alteridade que vem da experiência do 'alter ego', da condição de se ser outro a partir da perspectiva do próprio 'eu'. Isto implica na oposição entre 'identidade' e 'alteridade', cuja base é constituída pela 'intersubjetividade’ (DREHER, 2007). Ora, de acordo com Loenhoff (2017), no contato intercultural, em um primeiro momento, como reação à opacidade, estranheza e alteridade, a comparação cultural representa uma autoafirmação perante a ameaça da consciência crescente de que tudo também poderia ser diferente. É justamento este processo que observaremos em detalhe a seguir. 


\section{METODOLOGIA}

O projeto Comunicação (Inter-)Cultural em Interação foi iniciado em 2012 na $\mathrm{UFMG}^{7} \mathrm{O}$ principal alvo é a criação de um corpus de vídeos e suas transcrições, que se baseiam em interações entre participantes de culturas diferentes, bem como entre participantes que tenham o mesmo pano de fundo linguístico e cultural, para fins de comparação. No centro das conversas, de maioria eliciadas, estão tópicos interculturais. Dessa forma, busca-se revelar, como se constituem processos (auto-) reflexivos em dependência da língua e cultura, e como aparecem nas interações in situ sendo construídos pelos participantes de forma recíproca e multimodal no nível verbal, vocal e visual.

O trabalho foi iniciado em 2010 com um projeto piloto no qual filmamos duas interações entre quatro brasileiros e quatro alemães. Dois anos depois, estendemos o projeto também a outras nacionalidades. Os participantes são primeiramente pessoas que fazem parte de intercâmbios escolares (Youth for Understanding) ou estudantis (Ciências Sem Fronteiras, ERASMUS), e cooperamos com as respectivas diretorias de relações internacionais, p.ex. na UFMG, na UFV, ou na WWU (Westfälische Wilhelms-Universität Münster).

Depois das filmagens, as interações são transcritas no programa EXMARaLDA $^{8}$ (SCHMIDT; WÖRNER, 2009), seguindo as convenções de GAT 2 (SELTING et al.., 2016). ${ }^{9}$ Sendo assim, o corpus é criado em conjunto, mas cada membro desenvolve sua própria questão de pesquisa. Por parte, alguns dias após as filmagens, são realizadas entrevistas retrospectivas, nas quais os participantes são confrontados com as filmagens em grupo e devem comentar sobre o evento.

Até agora, realizamos estudos nos campos de code-switching, metacomunicação, (im-)polidez, estilos de conflito, metáforas e gestos, conceitualização de hotwords, construções de membership categorization na sala de aula de língua estrangeira e formas de estilização para falar sobre experiências de choques culturais.

As sequências que servem de base para a análise a seguir provêm de filmagens realizadas durante a minha estadia para o pós-doutorado na Universidade de Münster, Alemanha de 2013 a 2014, sob orientação da Profa. Dra. Susanne Günthner e com apoio do programa CAPES/HUMBOLDT Research Fellowship for experienced researchers. Realizamos quatro filmagens: a primeira com cinco intercambistas brasileiros do programa Ciências sem Fronteiras quando acabaram de chegar em Münster; a segunda com cinco estudantes alemães logo antes de sua saída para participar do intercâmbio do programa ERASMUS com países destinatários distintos. Nestas duas primeiras filmagens, as perguntas feitas foram voltadas para expectativas com relação a diferenças culturais quanto à vida universitária, à sociedade, à família, às relações amorosas, às amizades e

${ }^{7} \mathrm{O}$ site do projeto em português pode ser acessado em $<$ http://www.letras.ufmg.br/nucleos/ nucoi/>

${ }^{8}<$ www.exmaralda.com>

${ }^{9}$ Um resumo das convenções encontra-se no anexo.. 
à comunicação. As filmagens foram repetidas no final da estadia dos brasileiros em Münster, e no caso dos alemães, após a volta deles para Münster, dessa vez, nos dois casos, apenas com quatro dos participantes..$^{10}$ Os cartões que eliciaram a discussão continham as mesmas perguntas, só que dessa vez com relação às experiências reais.

\section{ANÁLISE}

\subsection{Os brasileiros invasivos}

O primeiro exemplo provém da segunda conversa entre quatro brasileiros no final da sua estadia na WWU. Trata-se de experiências reais na Alemanha. Os estudantes estão falando sobre a atitude divergente dos alemães perante seus interlocutores em comparação a brasileiros. B1, B2 e B3 são de sexo masculino e B4 é de sexo feminino ${ }^{11}$ :

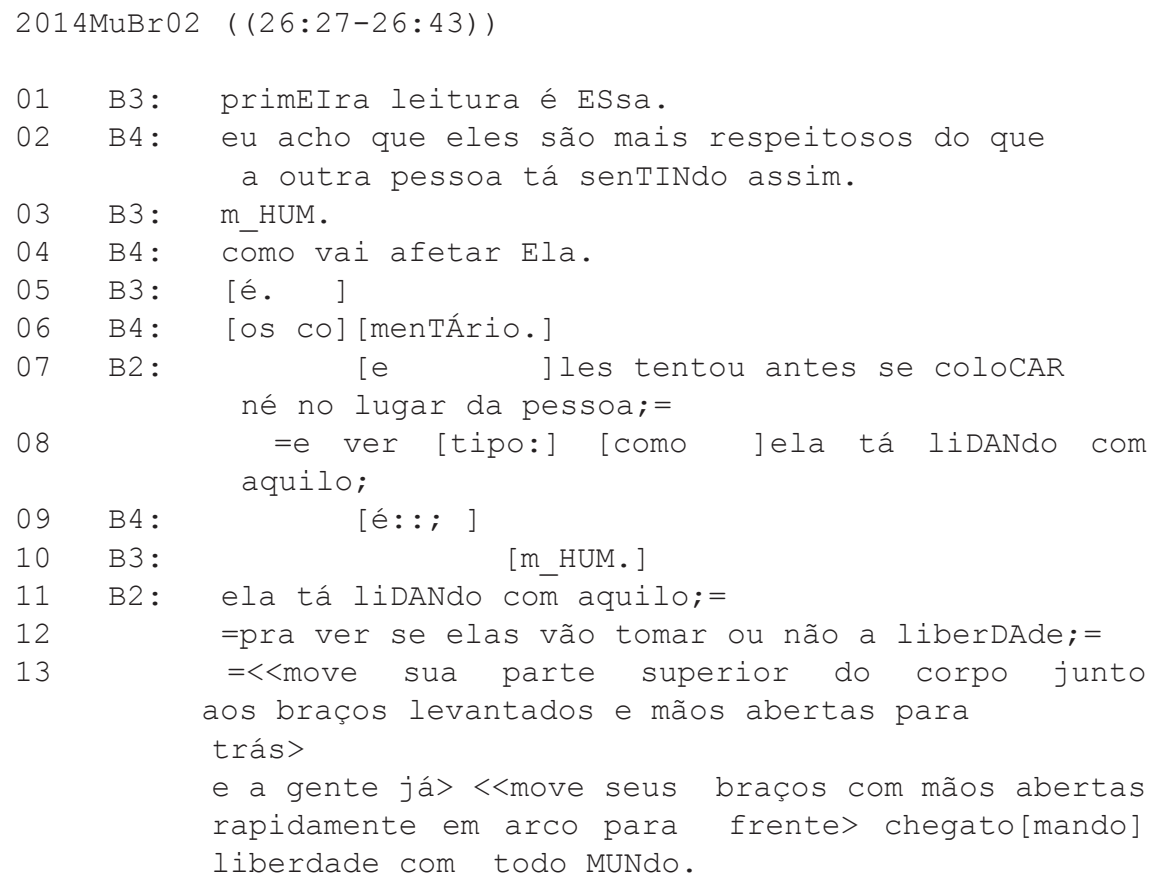

${ }^{10}$ Os participantes assinaram um TLCE (Termo de Consentimento Livre e Esclarecido) que continha informações detalhadas sobre o procedimento e a permissão com relação à divulgação científica dos resultados. O TLCE foi feito de acordo com as orientações do Comitê de Ética e Pesquisa da UFMG (COEP-UFMG).

11 "Os vídeos das três sequências a seguir podem ser assistidas no seguinte link: https://drive. google.com/folderview?id=0B4065pqma9RCd2dZZmZnQVZoZTg" 


\begin{tabular}{|c|c|c|}
\hline$\overline{14}$ & B1: & {$[((r i))$} \\
\hline 15 & B3: & {$[((r i))$} \\
\hline 16 & B4: & {$[<<r i n d o>$ é: :. $>$} \\
\hline 17 & B2: & {$[=\langle<$ rindo $>$ é indepenDENte; $=$ né, } \\
\hline 18 & B1: & {$[((r i))$} \\
\hline 19 & B4 & [é:: Totalmente isso \\
\hline
\end{tabular}

Na linha 02, no momento em que B4 atribui aos alemães as palavras de conteúdo abstrato respeitosos e senTINdo, ela acrescenta o marcador discursivo assim no final do turno. Neste contexto, para o PB, uma função importante do assim já foi descrita como a elaboração explicativa para o próximo turno (CASTELANO; LADEIRA, 2010, p. 12), o que pode ser aplicado aqui. O assim provavelmente dá a indicação de que o argumento colocado será explicitado de forma mais aprofundada a seguir. Porém, na linha 04, B4 continua sendo vaga e, finalmente, B2 toma o turno e introduz uma metáfora por meio da qual ele consegue comprimir e visualizar o ponto-chave. Em termos interacionais, a ideia crucial agora é coconstruída pelos dois participantes.

A palavra-chave acentuada é coloCAR, por meio da qual B2 desenha um espaço ocupado pelos alemães - uma imagem linguística para a suposta capacidade de antecipar a reação do outro. B4 reage por um 'token agreement' na linha 09, e também B3 incentiva B2 a prosseguir por meio do uso de um continuador na linha 10. Na linha 11, B2 repete o que disse anteriormente e toma tal repetição como ponto de partida para a elaboração de sua ideia: pra ver se elas vão tomar ou não a liberDAde. Com isso, a metáfora é ancorada coexpressivamente nos níveis verbal e gestual. Enquanto ele diz: e a gente já chega tomando liberdade com todo MUNdo, ele move para trás a parte superior do corpo junto aos braços levantados e às mãos abertas e, em seguida, os move para frente, como se fosse um animal selvagem que invadisse o território da sua vítima. De fato, como reação, tal gesto causa risos e aprovação dos coparticipantes.

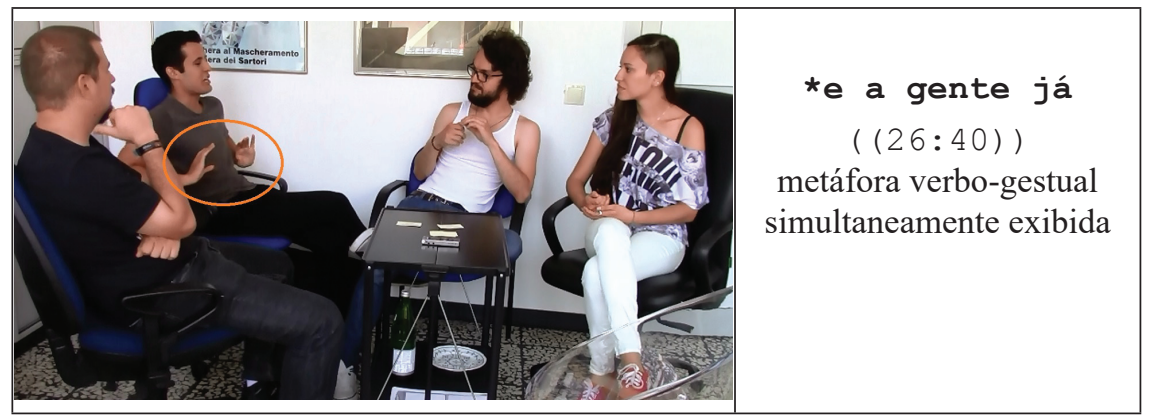



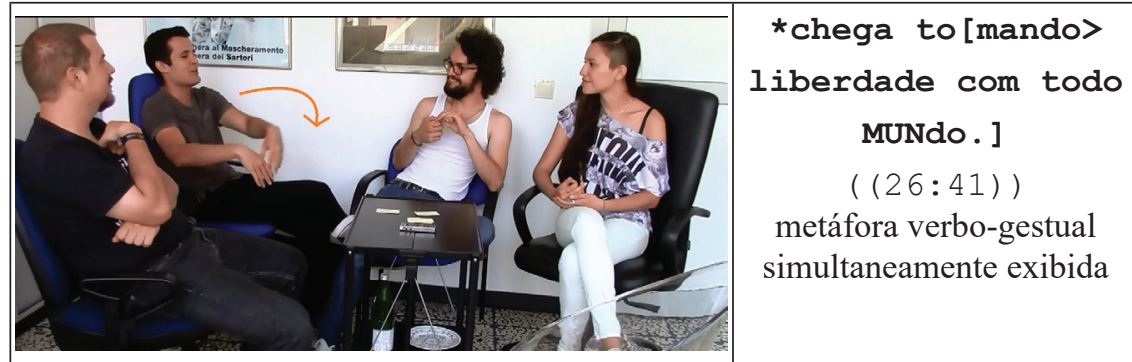

Figura 1: metáfora verbo-gestual - os brasileiros invasivos

À primeira vista, pode-se descrever esta metáfora de acordo com Müller e Cienki (2009) como uma 'verbo-gestural metaphor', uma vez que se observa claramente um interjogo da metáfora territorial em ambos os níveis. Não obstante, um olhar mais próximo revela que a metáfora gestual é muito mais complexa por transformar a ideia esquemática do 'tomar espaço' em uma invasão por ser vivo (KÖVECSES, 2005, p. 68; GRADY, 2005, 1608-1609). Adicionalmente, pode-se confirmar a hipótese de Mittelberg e Waugh, pois os movimentos gestuais esquemáticos apontam metonimicamente para o ataque como um todo, que, como segundo passo de inferência, é metaforicamente projetado para o comportamento dos brasileiros.

Um outro detalhe elucidativo aponta a reação imediata e simultânea dos coparticipantes e sugere que a imagem comprimida assuma uma função de "ponto de acesso ao conhecimento enciclopédico"12 (LANGACKER, 1987, p. 163-164) o que também corresponde à visão da metonímia como um hiperlink para uma cena maior, de acordo com PAIVA (2010). Convém salientar que há muitas interseções entre nosso conhecimento de senso comum e as teorias do campo da sociologia, como a teoria dos territórios segundo Goffman (1971), ou do campo da comunicação intercultural, como a teoria da proxêmica de Edward Hall (1966). Nós sabemos, pelo menos por meio de guias de viagem, jornais, revistas, internet, narrações de outros, filmes e documentários, que grupos culturais distintos também cultivam costumes territoriais divergentes. Hall (1966), por exemplo, analisou as relações animais e humanas no microespaço e também suas características culturais e revelou, entre outros, que norte- e sul-americanos cultivam zonas de tolerância distintas no que diz respeito à distância interpessoal. Em encontros de negócios entre norte- e sul-americanos, ao passo que norte-americanos buscavam sempre aumentar a distância interpessoal, os sul-americanos buscavam sempre reduzíla. Neste momento, parece que são ativados tais pré-conhecimentos que cada um de nós possui de forma particular, bem como nossos conhecimentos sobre as paralelas entre comportamentos animais e humanos. Adicionalmente, não apenas o falante, mas também os coparticipantes estão mostrando sua vasta experiência com a 'alteridade', não apenas quanto ao sentimento de estranheza que ela gera,

\footnotetext{
12 "point of access to encyclopaedic knowledge"
} 
como também em relação à ideia de que a alteridade implica a capacidade de um indivíduo se colocar no lugar do outro e descrever as diferenças entre a cultura de origem e a cultura de chegada a partir de um distanciamento de ambas as culturas. Este processo se reflete na própria metáfora escolhida por B2.

\subsection{Os suecos abertos}

O grau da formalidade no tratamento é outro campo sobre o qual se discorre frequentemente. No campo pragmático, com relação à dêixis social, as pesquisas foram iniciadas pelos estudos de Brown e Gilman (1960) sobre a diferença de $T / V$, seguidas pelas análises voltadas para o sistema japonês dos honoríficos como classe especial de palavras e como morfemas para indicar o status de uma pessoa (INOUE, 1974; SHIBATANI, 1994). Em relação a você versus o senhor/a senhora no Brasil, existe igualmente uma grande variedade de estudos de cunho regional, bem como histórico (LOPES, 2011; MODESTO, 2005; FARACO, 1996; SETTE; RIBERIO, 1984). Além das pesquisas sobre Du/Sie em alemão (BESCH, 1996; HARTUNG, 2001), há um estudo recente sobre as diferenças entre o alemão e o PB em perspectiva intercultural (ARANTES; SCHRÖDER, 2014): ao passo que a dicotomia do $\mathrm{Du} / \mathrm{Sie}$ indica uma divisão entre as esferas pública e privada na Alemanha, no Brasil, a dicotomia entre você/o senhor parece estar mais ligada a questões de formalidade e intimidade, bem como a relações assimétricas e simétricas.

Enquanto, no campo da Pragmática Intercultural, Triandis (1995) considera como ponto principal da diferença de $T / V$ as dimensões da formalidade e da intimidade, Wierzbicka (2003) se opõe a esta visão universalista de equiparar informalidade à intimidade, uma vez que, na visão dela, o you norte-americano, no fim das contas, apenas serve para manter todos à distância. Seja como for, nosso conhecimento de senso comum já incorporou estas etiquetas, criando dicotomias metafóricas como aquela de pessoas ou culturas abertas e fechadas, o que se reflete na seguinte sequência.

Aqui, cinco estudantes alemães conversam sobre suas expectativas logo antes da sua estadia no país anfitrião. O tema atual trata das possíveis diferenças no que tange a padrões de comunicação. A1 e A4 são de sexo masculino, enquanto A2, A3 e A5 são de sexo feminino. A5 relata que já entrou em contato por e-mail com sua universidade anfitriã na Suécia, e que ela já percebeu a partir desse contato que os suecos são mais diretos e informais, o que também se reflete no fato de que eles tratam do outro pelo primeiro nome:

2013MuAl01 ((44:32-45:13))

$$
\text { A5: }
$$$$
\text { also ich hab mit }
$$
geschriebn; então eu já troquei e-mails com a universidade

(-) und das war wirklich !SE:HR! sehr dirEkt.= e isso realmente foi muito muito direto 


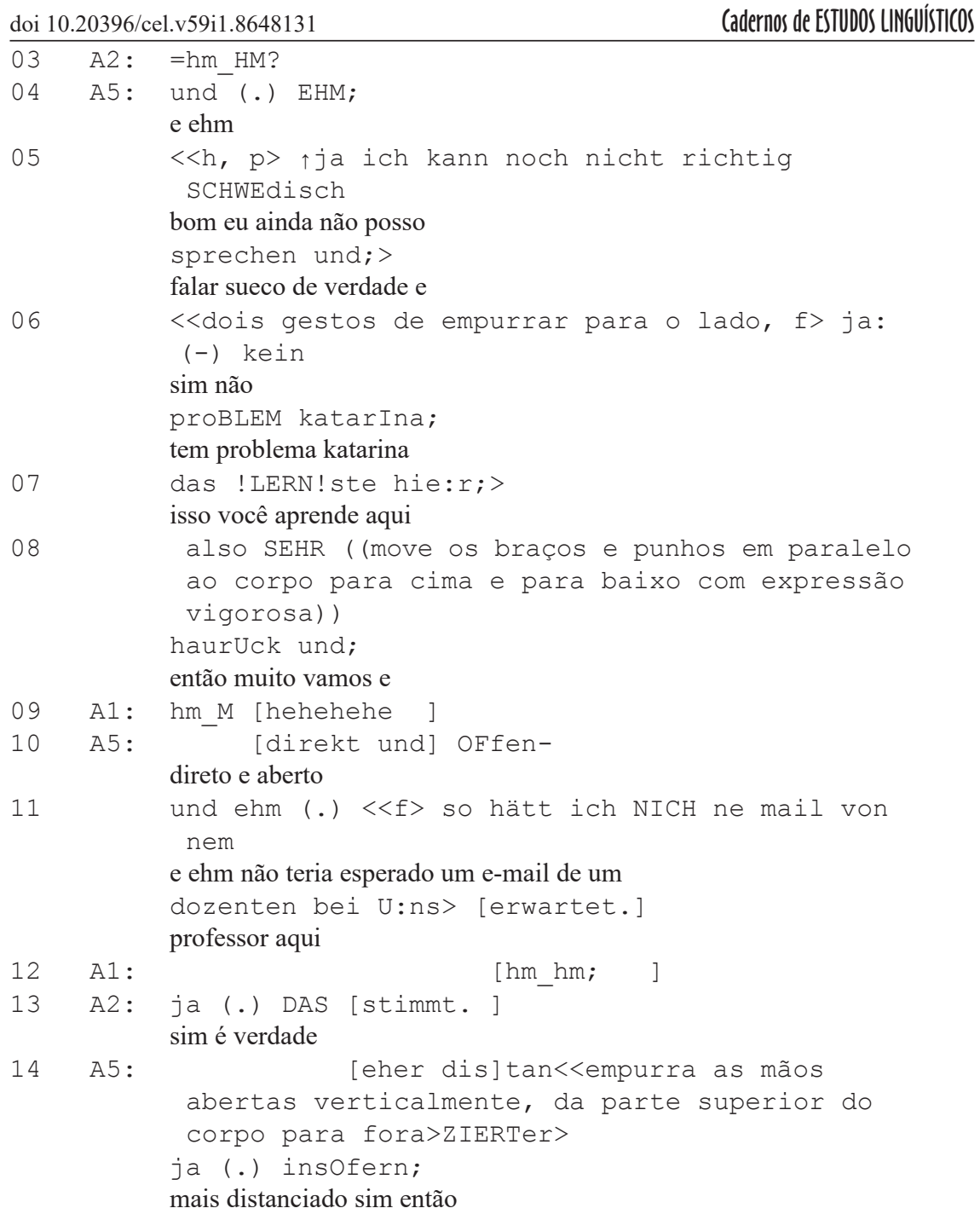

A sequência começa com uma corroboração de A5 com relação a uma enunciação anterior sobre sua impressão de que os suecos são mais diretos. Ela inicia uma narração sobre um e-mail que ela enviou para a universidade sueca e comenta que a resposta foi muito direta, prolongando o qualificador !SE:HR! (muito) e dando a ele um acento extra forte, o que causa o efeito de que a palavrachave cultural direto, a qual surge logo em seguida como cerne da narração, seja enfatizada (L02). A5 agora passa de uma 'report' para uma 'scenic presentation' (GÜNTHNER, 2011), o que tem como consequência uma apresentação mais emocionada da situação interpretada em termos culturais. Esta tendência é salientada pelo fenômeno que Günthner (1999; 2002), ao recorrer a Bakhtin (1981 
[1930]), analisa como 'sobreposição polifônica de vozes' (polyphonic layering of voices): A5 encena a entonação dos e-mails, caracterizando sua parte com uma frequência alta e uma voz sussurrada, indicando um caráter tímido e cuidadoso, enquanto a resposta da professora é marcada por uma voz alta junto a um acento extra forte na palavra !LERNste! (aprende), e não verbalmente por um gesto de empurrar para o lado (L06-07). Este gesto representa metonimicamente a força ilocucionária da ideia básica de abertura: todas as dúvidas são empurradas para o lado e o caminho está aberto para o novo meio social.

$\mathrm{Na}$ linha 08, o próximo gesto antecipa metonimicamente a expressão posterior haur $U c k^{13}$ no nível verbal. Neste gesto, os braços e os punho movem-se paralelamente ao corpo para baixo, e sublinham, assim, a atitude aberta e imediata refletida na resposta sueca. Novamente, o ouvinte tem que passar por dois passos para entender a metáfora multimodal verbo-gestual: primeiro, nos dois níveis, a expressão em si apresenta apenas uma pista de contextualização metonímica, Hauruck, como expressão exclamativa rítmica, que se usa na realização de um ato de força em conjunto. No seu resumo na linha 10, A5 finalmente usa explicitamente as expressões direkt (direto) e offen (aberto). Aqui, os dois conceitos corriqueiros estão interligados através do esquema imagético subjacente CULTURAS SÃO CONTÊINERES. Com base em nossa experiência antropológica fundamental do esquema DENTRO-FORA, que se baseia no fato de que estamos delimitados do nosso meio por nosso corpo e nossa pele, conceitualizamos também nossa experiência com o mundo conforme este esquema: olhamos em caixas e quartos, enchemos copos com água, colocamos objetos em estantes ou os pegamos de lá, entramos em casas e saímos delas, comemos e bebemos (JOHNSON, 1987, p. 19-30). Ora, com este ponto de partida, começamos a estender este esquema também a domínios abstratos: a categorias, ao espírito, à personalidade (LAKOFF; JOHNSON, 1999), a famílias, a classes sociais e, finalmente, a culturas (MARSCHAK, 2005, p. 321; SCHRÖDER; CARNEIRO MENDES, 2015).

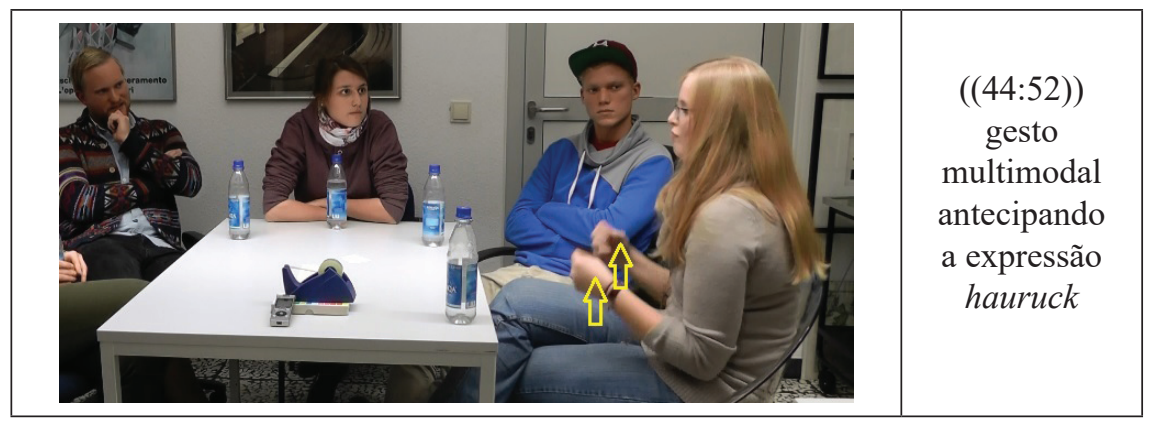

${ }^{13}$ Expressão exclamativa não traduzível, usada como interjeição motivadora em momentos de trabalho manual pesado que precisa ser realizado em conjunto. 


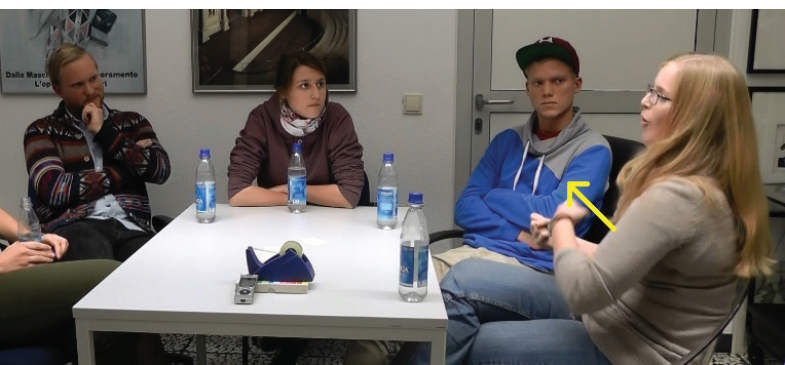

$((44: 52))$

gesto

multimodal

antecipando

a expressão

hauruck

Figura 2: gesto multimodal - hauruck

Por fim, na linha 14, A5 executa um último gesto, no qual ela empurra as palmas das mãos abertas verticalmente, indo da parte superior do corpo para fora, ao se referir, no nível verbal, aos alemães 'distantes'. Com isso, em um primeiro passo, ela se refere metonimicamente a uma linha fronteiriça demarcando um território que outros não podem ultrapassar, e que, em um segundo passo, representa metaforicamente a atitude distante dos alemães. Novamente, especialmente pelo uso do gesto metafórico, tornam-se reveladas a posição do observador e a experiência de 'alteridade' a partir de um posicionamento reflexivo ao comparar as duas culturas, o que implica o próprio comportamento descrito agora a partir de um ângulo retrospectivo.

\subsection{Os alemães diretos}

$\mathrm{Na}$ última sequência, cinco brasileiros falam sobre suas expectativas logo após sua chegada em Münster. B1, B3, B4 e B5 são do sexo masculino e B2 é do sexo feminino. B2 volta para a pergunta no cartão que tematiza possíveis diferenças quanto a padrões comunicativos, e comenta a dicotomia 'direto/indireto':

\section{$2014 \operatorname{MuBr} 01 \quad((18: 06-18: 15))$}

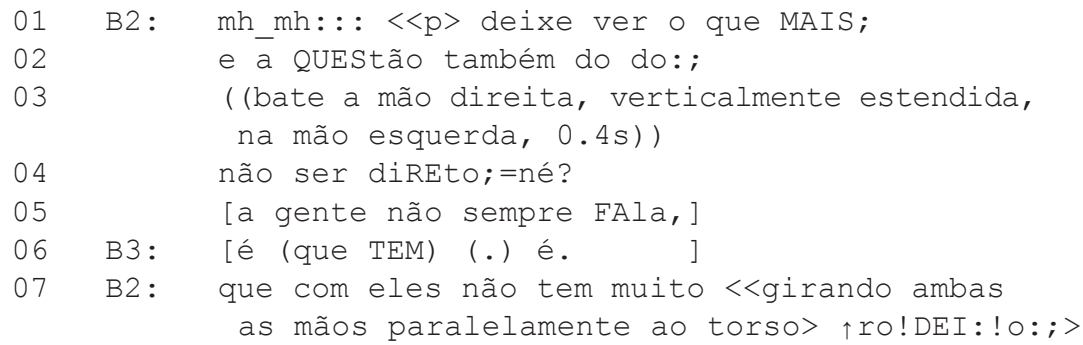

Em termos semânticos, temos um caso interessante aqui, pois a palavra direto, seja em alemão, seja em português, tem uma base metafórica, mesmo que opaca, ao apresentar o que Cornelia Müller (2004) chama de 'sleeping metaphor'. E aqui, observa-se como se dá o processo do despertar da metáfora. Primeiramente, 
como conceito-chave cultural, a palavra direto é enfatizada prosodicamente pelo acento, e também verbalmente pelo anúncio metacomunicativo na linha 02 e a QUEStão também do, que age como pista de contextualização ao reativar a metáfora. O significado original de direto, 'em linha reta, reto; numa determinada direção, sem desvios’ (HOUAISS et al., 2009, p. 691), é ampliado de forma não verbal: a mão direita desenha uma linha reta que vai de encontro à mão esquerda, exprimindo clareza e objetividade. Em uma segunda etapa, B2 desenvolve a metáfora ao esquematizar então a atitude oposta para atribuir aos brasileiros a característica contrária: não tem muito ro!DEI:!o. Aqui a metáfora é elaborada coexpressivamente no nível gestual pelas mãos se movendo em círculos. Os dois esquemas estão interligados e ancorados corporalmente, como destaca Johnson (2005, p. 20): "Nós experimentamos e inferimos algo sobre MOVIMENTO RETILÍNEO [...] e inferimos algo diferente sobre movimentos curvilíneos ou desviados que não têm destino óbvio (relativo a um esquema FONTE-CAMINHO-ALVO)." 14 Lakoff (1987, p. 269-303) destaca que a DIREÇÃo apresenta a constituinte básica para o esquema CAMINHO e demonstra de que forma este esquema serve como base para metáforas através das quais FINALIDADES são concebidas em termos de DESTINOS.

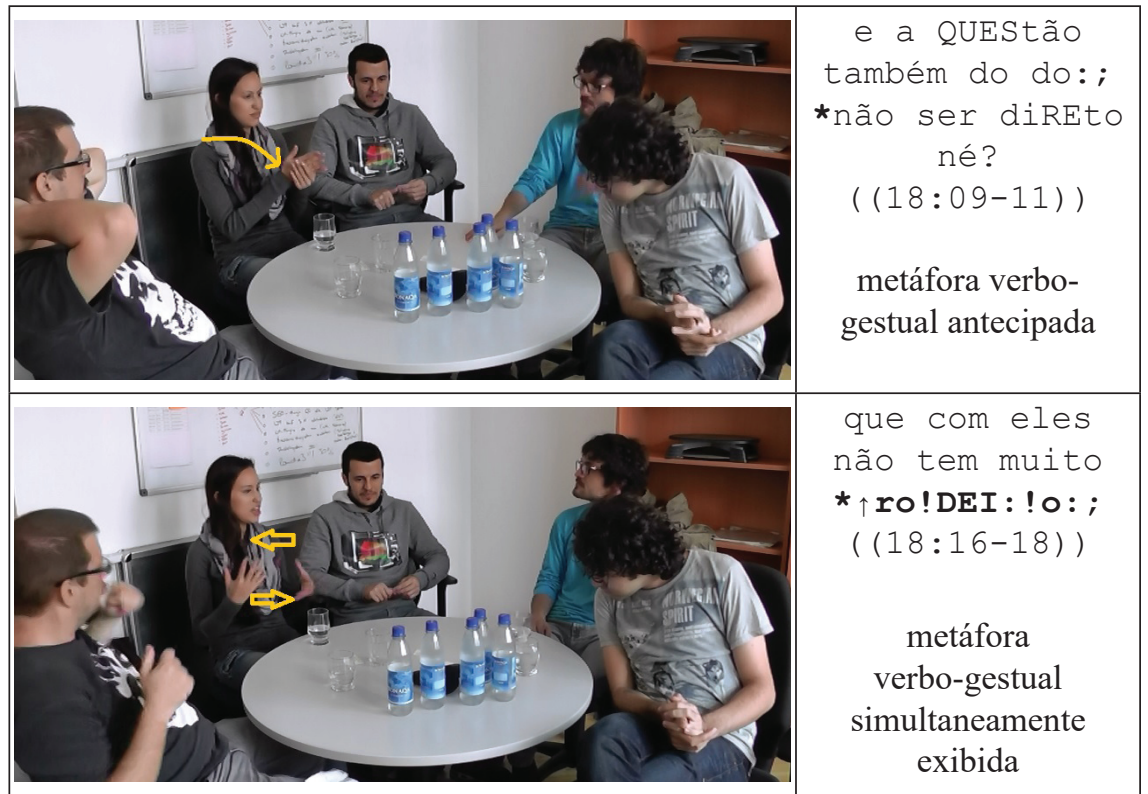

Figura 3: metáfora verbo-gestual - alemães diretos e brasileiros indiretos

Esta distinção metafórica também já entrou no campo dos estudos da Pragmática Intercultural, aduzindo dados de estilos de fala direta e indireta

14 "We experience and draw inferences about RECTILINEAR MOTION [...] and draw different inferences about curved motions or deviating motions that have no obvious goal (relative to a SOURCE-PATH-GOAL schema).” 
relacionados a culturas específicas, especialmente considerando alemão em comparação a outras línguas, como inglês (HOUSE, 2003; HOUSE; KASPER, 1981; HOUSE, 2010; BENNETT, 1998), japonês e grego (MARKOWSKY; THOMAS, 1995), ou chinês (GÜNTHNER, 2008), para denominar apenas alguns trabalhos. House (2010, p. 571), por sua vez, resume seus estudos crossculturais sobre diferenças nos estilos britânico e alemão até o momento atual ao estabelecer quatro dimensões que correspondem ao estilo alemão, sendo elas: (1) 'Ser direto' (Directness); (2) 'Orientação para si mesmo' (Orientation toward Self); (3) 'Conteúdo' (Content); e (4) 'Explicitude' (Explicitness), ao passo que o estilo britânico é caracterizado por outras quatro dimensões: (1) 'Ser indireto' (Indirectness); (2) 'Orientação para o outro' (Orientation toward Other); (3) 'Destinatários' (Addressees); e (4) 'Implicitaude' (Implicitness). A respeito de uma comparação entre os estilos alemão e brasileiro, análises empíricas (MEIRELES, 2001, 2016; CARVALHO; TRAVISAN, 2003; SCHRÖDER, 2003, 2014a, 2014b) revelaram que, resumindo e adotando a terminologia de Spencer-Oatey (2008), o estilo brasileiro pode ser caracterizado por um 'realce da harmonia' (rapport enhancement) e 'orientação para manutenção da harmonia' (rapport maintenance orientation) mais alta, em oposição a uma 'orientação para negligenciamento da harmonia' (rapport neglect orientation) e 'orientação para desafiação da harmonia' (rapport challenge orientation) mais alta no caso alemão. Como este tópico é amplamente debatido no contexto da aprendizagem da língua estrangeira, não surpreende que estas orientações de valores culturais sejam mencionadas explicitamente durante a conversa entre os cinco intercambistas brasileiros, as quais podem prefigurar a experiência de 'alteridade' que, neste caso, ainda não se iniciou através de contatos pessoais.

\section{CONSIDERAÇÕES FINAIS}

O objetivo deste trabalho foi demonstrar como, em estudos empíricos sobre comunicação intercultural em interação situada, a Linguística Cognitiva e a Análise da Conversa podem ser interligadas. Para tal, busquei escolher momentos altamente reflexivos da experiência da alteridade, os quais foram analisados a partir de conversas reais, eliciadas e com foco na sua multimodalidade contextualizada.

Vimos que os participantes, quando recorrem ao seu 'stock of knowledge at hand' (SCHÜTZ, 1971), de fato se referem a categorias como DIRETO e INDIRETO, que se baseiam em esquemas imagéticos como SOURCE-PATH-GOAL, o qual já foi abordado detalhadamente na Semântica Cognitiva. O mesmo vale para o conceito de pessoas ABERTAS e FECHADAS, uma ideia que se deve ao esquema imagético de um grupo cultural como CONTÊINER. Concomitantemente, ilustrei como tal conhecimento é 'engatilhado', isto é, em conversas em andamento, prétipificações são ativadas reciprocamente quando novas experiências são tornadas compreensíveis. Com isso, também metáforas gestuais são utilizadas e assumem o papel de compressões e concretizações na produção situada do sentido. Todavia, não se trata apenas de uma mera ativação de estruturas convencionais, mas também 
da elaboração e do desenvolvimento das metáforas acordadas que, no contexto dado, assumem tarefas específicas, como vimos especialmente no último exemplo. Por outro lado, no primeiro exemplo, mostrou-se como uma imagem concreta pode variar a partir de um esquema básico, no caso dado, o desenvolvimento da metáfora genérica TERRITÓRIO para a metáfora complexa INVASÃO POR UM ANIMAL SELVAGEM. O caráter inovativo desta metáfora vem à tona especialmente por meio da reação dos coparticipantes, que ratificaram a metáfora por risos.

Além disso, todos os exemplos revelaram também o papel indispensável que o processo metonímico inferencial assume na construção de sentido. Frequentemente, a compressão fractal metonímica parece até ser o ponto decisivo do acesso cognitivo para a compreensão do cenário metafórico integral que emerge do discurso.

Por fim, um aspecto relevante e elucidativo que este estudo revelou foi que os intercambistas dispõem de modelos culturais incorporados de forma multimodal. Trata-se de modelos da sua própria cultura, assim como da cultura de chegada, o que aponta para a alta reflexividade interligada à experiência da 'alteridade'. Isto traz implicações para o ensino e a aprendizagem de línguas estrangeiras: por um lado, não se pode reduzir a parte cultural do ensino a uma lista de cunho 'funcionalista' que compreenda comportamentos aceitáveis e não aceitáveis na cultura de chegada, pois não somos rôbos, e tal procedimento contraria nossa complexidade cognitiva; por outro lado, também não se pode ensinar a fórmula promissora de que no fundo, todas as culturas são iguais, uma vez que este ideal ilusório implica desmentir a realidade multifacetada e, às vezes, conflituosa, além de declarar diferenças per se como algo problemático, embora essas diferenças possam ter um lado bastante construtivo e excitante.

Ao invés disso, esperamos contribuir para uma abordagem reflexiva e cognitiva, que leve o aluno a sério e tome em consideração seu estoque de conhecimento prévio, rico e diverso, que almeje estabelecer uma posição entre as culturas em questão e ensine para quem experiencia a alteridade as múltiplas camadas da cultura de chegada, simultaneamente a um questionamento dos próprios sistemas de relevância, de modo a criar um espaço da interculturalidade, o qual o filósofo Hans-Georg Gadamer (1960, p. 279) chama de "verdadeiro lugar da hermenêutica". ${ }^{15}$ Tal abordagem representaria o primeiro passo em direção a uma conscientização que possibilite a transformação do alheio em algo familiar, e do familiar em algo contingente, ou seja, em termos de Gadamer, algo que leve à 'fusão dos horizontes' (Horizontverschmelzung).

\section{REFERÊNCIAS BIBLIOGRÁFICAS}

ARANTES, Poliana Coeli Costa; SCHRÖDER, Ulrike. A dêixis social em sala de aula de ALE: propostas para uma unidade de ensino In: MOURA, Magali; SALIÉS, Tânia Gastão; STANKE, Roberta Sol; BOLACIO, Ebal (Org.). Esino-Aprendizagem de Alemão como Lingua Estrangeira: Teoria e Práxis. Rio de Janeiro: Letra Capital. 2014. p. 176-198.

15 "wahre Ort der Hermeneutik" 
BAKHTIN, Mikhail M. The Dialogic Imagination: Four Essays. Ed. Michael Holquist. Trans. Caryl Emerson and Michael Holquist. Austin, London: University of Texas Press, 1981 [1930].

BESCH, Werner. Duzen, Siezen, Titulieren. Zur Anrede im Deutschen heute und gestern. Göttingen: Vandenhoeck \& Ruprecht, 1996.

BROWN, Roger; GILMAN, Albert. The pronouns of power and solidarity. In: SEBEOK, Thomas A. (Org.). Style in Language. Cambridge, MA: MIT Press. 1960. p. 253-276.

CAMERON, Lynne. Confrontation or complementarity? Metaphor in language use and cognitive metaphor theory. Annual Review of Cognitive Linguistics, v. 5, p. 107-135. 2007.

CAMERON, Lynne. Metaphor and talk. In: GIBBS, Raymond W. Jr. (Org.). The Cambridge Handbook of Metaphor and Thought. Cambridge: Cambridge University Press. 2008, p. 197-211.

CAMERON, Lynne; Deignan, ALICE. Combining Large and Small Corpora to Investigate Tuning Devices Around Metaphor in Spoken Discourse. Metaphor And Symbol, v. 18, n. 3, p. 149-160. 2003.

CARVALHO, Marília G.; TREVISAN, Lino. Relações interculturais entre trabalhadores brasileiros e alemães na VW-Audi de S. José dos Pinhais. Revista Educação \& Tecnologia, v. 7, p. 68-86. 2003.

CASTELANO, Karine L.; LADEIRA, Wânia T. Funções discursivo-interacionais das expressões "assim", "tipo" e "tipo assim" em narrativas orais. Letra Magna: Revista de Divulgação Cientifica em Lingua Portuguesa, Linguística e Literatura, v. 06, n. 12, 2010, p. 1-17.

CIENKI, Alan. Metaphoric gestures and some of their relations to verbal metaphoric expressions. In: KOENIG, Jean-Pierre (Org.). Discourse and cognition: Bridging the gap. Stanford: Center for the Study of Language and Information. 1998, p.189-204.

CIENKI, Alan. Why study metaphor and gesture? In: CIENKI, Alan; MÜLLER, Cornelia Müller (Org.). Metaphor and Gesture. Amsterdam \& Philadelhpia: John Benjamins. 2008. p. 5-25.

DREHER, Jochen. Konstitutionsprinzipien 'kultureller Differenz': Zur Analyse der Konstruktion kultureller Grenzbestimmungen in grundlagentheoretischer Absicht. In: DREHER, Jochen; STEGMAIER, Peter (Org.). Zur Unüberwindbarkeit kultureller Differenz. Grundlagentheoretische Reflexionen. Bielefeld: transcript Verlag. 2007, p. 129-151.

FARACO, Carlos Alberto. O tratamento você em português: uma abordagem Histórica. Fragmenta, v. 13, Publicação do Curso de Pós-Graduação em Letras da UFPR. Curitiba: Editora da UFPR, 1996.

GADAMER, Hans Georg. Wahrheit und Methode. Grundzüge einer philosophischen Hermeneutik. Tübingen: J.C.B.Mohr (Paul Siebeck), 1960.

GARCEZ, Pedro M. A Perspectiva da Análise da Conversa Etnometodológica sobre o Uso da Linguagem em Interação Social, in: LODER, Letícia L.; JUNG, Neiva M. (Org.). Fala-emInteração Social. Introdução à Análise da Conversa Etnometodológica. Campinas: Mercado de Letras. 2008, p. 17-38.

GOFFMAN, Erving. Relations in Public: Microstudies of the Public Order. New York: Basic Books, 1971. 
GRADY, Joseph E. Primary metaphors as inputs to conceptual integration. Journal of Pragmatics, v. 37, 2005, p. 1595-1614.

GÜNTHNER, Susanne. Polyphony and the 'layering of voices' in reported dialogues: An analysis of the use of prosodic devices in everyday reported speech. Journal of Pragmatics, v. 31, 1999, p. 685-708.

GÜNTHNER, Susanne. Stimmenvielfalt im Diskurs. Formen der Stilisierung und Ästhetisierung in der Redewiedergabe. Gesprächsforschung. Online-Zeitschrift zur verbalen Interaktion, v. 3, 2002, p. 59-80.

GÜNTHNER, Susanne. Negotiating Rapport in German-Chinese Conversation. In: SPENCEROATEY, Helen (Org.). Culturally Speaking. Culture, Communication and Politeness Theory. London: Continuum. 2002. p. 207-226.

GÜNTHNER, Susanne. The Construction of Emotional Involvement in Everyday German Narratives - Interactive Uses of 'Dense Constructions'. Pragmatics, v. 21, n. 4, 2011, p. 573-592.

HALL, Edward T. The Hidden Dimension. Garden City: Anchor Books, 1966.

HARTUNG, Martin. Formen der Adressiertheit der Rede. In: BRINKER, Klaus; ANTOS, Gerd; HEINEMANN, Wolfgang; SAGER, Sven F. (Org.). Text- und Gesprächslinguistik. Linguistics of Text and Conversation. Ein internationales Handbuch zeitgenössischer Forschung. An International Handbook of Contemporary Research. Berlin, New York: Walter de Gruyter. 2001, p. $1348-1355$.

HOUAISS, Antônio; VILLAR, Mauro de Salles; MELLO FRANCO, Francisco Manuel de. Dicionário Houaiss da língua portuguesa. Rio de Janeiro: Objetiva, 2009.

HOUSE, Juliane. Misunderstanding in intercultural university encounters. In: HOUSE, Juliane House; KASPER, Gabriele (Org.). Misunderstanding in Social Life. Discourse Approaches to Problematic Talk. London: Longman. 2003, p. 22-56.

HOUSE, Juliane. Impoliteness in Germany: Intercultural encounters in everyday and institutional talk. Intercultural Pragmatics, v. 7, n. 4, 2010, p. 561-595.

HOUSE, Juliane; KASPER, Gabriele. Politeness markers in English and German. In: COULMAS, Florian (Org.). Conversational Routine. Berlin: Mouton de Gruyter. 1981. p. 157-186.

INOUE, Kazuko. Innovating Uses of Japanese Honorifics and Polite forms. Papers in Japanese Linguistics, v. 4, 1974, p. 19-41.

JOHNSON, Mark. The Body in the Mind: The Bodily Basis of Meaning, Imagination, and Reason. Chicago: University of Chicago Press, 1987.

JOHNSON, Mark. The philosophical significance of image schemas. In: HAMPE, Beate; GRADY, Joseph E. (Org.). From Perception to Meaning. Image Schemas in Cognitive Linguistics. Berlin \& New York: Mouton de Gruyter. 2005. p. 15-33.

KÖVECSES, Zoltán. Metaphor in Culture. Universality and Variation. Cambridge: Cambridge University Press, 2005.

KÖVECSES, Zoltán; RADDEN, Günther. Metonymy: developing a cognitive linguistic view. Cognitive Linguistics, v, 9, 1998, p. 37-77. 
LAKOFF, George. Women, Fire and Dangerous Things: What Categories Reveal about the Mind. Chicago: University of Chicago Press, 1987.

LAKOFF, George; JOHNSON, Mark. Metaphors We Live By. Chicago: The University of Chicago Press, 2003 [1980].

LAKOFF, George; JOHNSON, Mark. Philosophy in the Flesh. The Embodied Mind and its Challenge to Western Thought. New York: Basic Books, 1999.

LANGACKER, Ronald W. Foundations of Cognitive Grammar. Volume I: Theoretical Prerequisites. Stanford: Stanford University Press, 1987.

LOENHOFF, Jens. Comparação cultural e comunicação intercultural. Traduzido do alemão para o português de Ulrike Schröder, Paula Carvalho Tavares e Danilo Rocha Campanha. Original de 2003. In: SCHRÖDER, Ulrike; CARNEIRO MENDES, Mariana (Org.). Comunicação (Inter-) Cultural em Interação. Belo Horizonte: Editora da UFMG; no prelo.

LOPES, Célia Regina dos Santos. Tradição discursiva e mudança no sistema de tratamento do português brasileiro: Definindo perfis comportamentais no início do século XX. ALFA, v. 55, n. 2, 2011, p. 361-392.

MANDELBROT, Benoit B. The Fractal geometry of nature. W.H. Freeman and Company, 1982.

MARKOWSKY, Richard; THOMAS, Alexander. Studienhalber in Deutschland. Interkulturelles Orientierungstraining für amerikanische Studenten, Schüler und Praktikanten. Heidelberg: Asanger, 1995.

MARSCHARK, Marc. Metaphors in sign language and sign language users: A window into relations of language and thought. In: COLSTON, Herbert L.; KATZ, Albert N. (Org.). Figurative language comprehension: Social and cultural influences. Mahwah, NJ: Lawrence Erlbaum Associates, 2005, p. 209-234.

MCNEILL, David. Hand and mind: What gestures reveal about thought. Chicago: University of Chicago Press, 1992.

MEIRELES, Selma Martins. A negação sintática em diálogos do alemão e do português do Brasil. Pandaemonium Germanicum, v. 5, 2001, p. 139-168.

MEIRELES, Selma M. Uso de verbos com valor epistêmico no Trabalho da Face por falantes alemães e brasileiros, in: GALLE, Helmut P. E.; PEREIRA, Valéria S. (Org.). Anais do I Congresso da $A B E G$. São Paulo: ABEG Editora Associação Brasileira de Estudos Germanísticos (ABEG) 1, 2016, p. 395-401.

MITTELBERG, Irene; WAUGH, Linda R. Metonymy first, metaphor second: A cognitive-semiotic approach to multimodal figures of though in co-speech gesture. In: FORCEVILLE, Charles J.; URIOS-APARISI, Eduardo (Org.). Multimodal Metaphor. Berlin, New York: Mouton de Gruyter. 2009. p. 329-355.

MODESTO, Artarxerxes Tiago Tácito. Notícias de estudos realizados sobre as formas de tratamento no português brasileiro. Revista Letra Magna. Revista Eletrônica de Divulgação Científica em Língua Portuguesa, Lingüística e Literatura, v. 2, n. 2, 2005, p. 1-9.

MÜLLER, Cornelia. Redebegleitende Gesten: Kulturgeschichte - Theorie - Sprachvergleich. Berlin: Arno Spitz, 1998. 
MÜLLER, Cornelia. Forms and uses of the palm up open hand: A case of a gesture family? In: MÜLLER, Cornelia; POSNER, Roland (Org.). Semantics and Pragmatics of Everyday Gestures. Berlin: Weidler. 2004, p. 234-256.

MÜLLER, Cornelia. Gestures as a medium of expression: The linguistic potential of gestures. In: MÜLLER, Cornelia; CIENKI, Alan; FRICKE, Ellen; LADEWIG, Silvia; MCNEILL, David; TESSENDORF, Sedinha (Org.). Body - Language - Communication. An International Handbook on Multimodality in Human Interaction. Volume 1. Berlin \& Boston: De Gruyter Mouton. 2013, p. 202-217.

MÜLLER, Cornelia; CIENKI, Alan. Words, gestures, and beyond: Forms of multimodal metaphor in the use of spoken language. In: FORCEVILLE, Charles; URIOS-APARISI, Edurado (Org.). Multimodal Metaphor. Berlin \& New York: Mouton de Gruyter. 2009. p. 297-328.

PAIVA, Vera Lúcia Menezes de Oliveira. A Metonímia como processo fractal multimodal. Veredas, v. 01,2010 , p. $7-19$.

SACKS, Harvey. Lectures on Conversation. Volume 2. Oxford: Basil Blackwell, 1995.

SCHMIDT, Thomas; WÖRNER, Kai. EXMARaLDA - Creating, analysing and sharing spoken language corpora for pragmatic research. Pragmatics, v. 19, 2009, p. 565-582.

SCHRÖDER, Ulrike. Brasilianische und deutsche Wirklichkeiten. Eine vergleichende Fallstudie zu kommunikativ erzeugten Sinnwelten. Wiesbaden: Deutscher Universitätsverlag, 2003.

SCHRÖDER, Ulrike. Kommunikationstheoretische Fragestellungen in der kognitiven Metaphernforschung. Eine Betrachtung von ihren Anfängen bis zur Gegenwart. Tübingen: Gunter Narr Verlag, 2012.

SCHRÖDER, Ulrike. Interkulturelle Kommunikation zwischen Deutschen und Brasilianern im Lichte von Strategien der (Un-)höflichkeit, divergierenden Konfliktstilen und Formen des Beziehungsmanagements. In: FÖLDES, Csaba (Org.). Interkulturalität unter dem Blickwinkel von Semantik und Pragmatik. Tübingen: Narr, Francke Attempto. 2014a, p. 207-224.

SCHRÖDER, Ulrike. The interplay of politeness, conflict styles, rapport management and metacommunication in Brazilian-German interaction. Intercultural Pragmatics, v. 11, 2014b, p. $57-82$.

SCHRÖDER, Ulrike; CARNEIRO MENDES, Mariana. A utilização da metáfora CULTURA É UM CONTÊINER e sua contextualização multimodal em uma interação intercultural: uma análise a partir das perspectivas comunicativas e extracomunicativas. Antares, vol. 7(14), p. 107-128, 2015; http://www.ucs.br/etc/revistas/index.php/antares/article/viewArticle/3829; acesso em 16 de março de 2017.

SELTING, Margret et al. Um sistema para transcrever a fala-em-interação: GAT 2. Traduzido e adaptado por Ulrike Schröder, Mariana Carneiro Mendes, Caroline Caputo Pires, Diogo Henrique Alves da Silva, Thiago da Cunha Nascimento e Flavia Fidelis de Paula, com revisão técnica de Paulo Cortes Gago (UFJF/UFRJ). Veredas, v. 20, n. 2, p. 6-61, 2016; acesso em 16 de março de 2017.

SETTE, Neide M. Durães; RIBEIRO, M. Sophie Guieu C. T. Interação face-a-face: simetria/assimetria. Cadernos de Estudos Linguísticos, v. 7, 1984, p. 87-105. 
SHIBATANI, Masayoshi. Honorifics. In: ASHER, Ronald E.; SIMPSON, James M. Y. (Org.). The Encyclopedia of Language and Linguistics. Oxford \& New York: Pergamon Press. 1994, p. 1600-1608.

SPENCER-OATEY, Helen. Face, (im)politeness and rapport. In: SPENCER-OATEY, Helen (Org.). Culturally Speaking. Culture, Communication and Politeness Theory. London: Continuum. 2008, p. 11-47.

TRIANDIS, Harry C. Individualism and Collectivism, Boulder: Westview, 1995.

WIERZBICKA, Anna. Cross-Cultural Pragmatics. The Semantics of Human Interaction. Berlin: Mouton de Gruyter, 2003. 


\section{Resumo das convenções de transcrição de GAT 2}

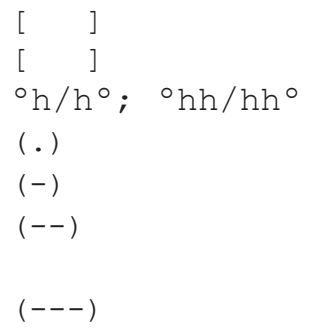

$(0.5) /(2.0)$

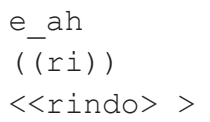

$(\mathrm{xxx} \quad \mathrm{xx} \mathrm{x})$

(posso)

$=$

:

: :

: : :

?

Sílaba

sílaba

! Síl laba

?

,

$-$

;

•

$\uparrow$

$\downarrow$

$<<1>>$

$<\langle\mathrm{h}\rangle>$

en ' $\mathrm{T} \tilde{\mathrm{A} O}$

en' $\mathrm{T} \tilde{\mathrm{AO}}$

en-T̃̃O sobreposição e fala simultânea

ins-/expiração em dependência da duração micro pausa estimada em até 0,2 seg de duração aprox. pausa curta estimada em aprox. 0,2-0,5 seg de duração pausa intermediária estimada em aprox. 0,5 - 0,8 seg de duração

pausa longa estimada em aprox. 0,8 - 1,0 seg de duração

pausa mensurada em aprox. 0,5/2,0 seg de duração (até o décimo de segundo)

cliticizações dentro de unidades

descrição de atividades não verbais

descrição de atividades acompanhando a fala com indicação de

escopo

duas sílabas incompreensíveis

termo presumido

continuação rápida e imediata com um novo turno ou segmento (latching)

alongamento, de aprox. 0,2-0,5 seg.

alongamento, de aprox. 0,5-0,8 seg.

alongamento, de aprox. 0,8-1,0 seg.

ruptura (cut-off) por fechamento glotal

acento focal

acento secundário

acento focal extra forte

movimento entonacional final alto ascendente

movimento entonacional final ascendente

movimento entonacional final nivelado

movimento entonacional final descendente

movimento entonacional final baixo descendente

pulo entonacional para cima

pulo entonacional para baixo

frequência mais baixa

frequência mais alta

movimento entonacional descendente

movimento entonacional ascendente

movimento entonacional nivelado 
en^T⿱艹八O

en ${ }^{`} \mathrm{TÃO}$

$<<\mathrm{f}>$

$<<$ all $>>$

$<<$ len $>\quad>$

$<<$ cresc $>>$

$<<$ dim $>\quad>$

$<\langle\operatorname{acc}\rangle \quad>$

$\langle<\operatorname{rall}\rangle>$ movimento entonacional ascendente-descendente movimento entonacional descendente-ascendente forte, alto

allegro, rápido

lento, devagar

crescendo, aumentando o volume

diminuendo, diminuindo o volume

accelerando, aumentando a velocidade

rallentando, diminuindo a velocidade

Recebido: $13 / 01 / 2017$

Aceito: $21 / 03 / 2017$ 